DOI $10.52727 / 2078-256 X-2021-17-3-43-43$

\title{
ПРОГРЕССИРОВАНИЕ ХРОНИЧЕСКОЙ СЕРДЕЧНОЙ НЕДОСТАТОЧНОСТИ У БОЛЬНЫХ АРТЕРИАЛЬНОЙ ГИПЕРТОНИЕЙ В СОЧЕТАНИИ С ФИБРИЛЛЯЦИЕЙ ПРЕДСЕРДИЙ
}

\author{
Л.Д. Хидирова, Д.А. Яхонтов \\ ФГБОУ ВО «Новосибирский государственный медицинский университет», Минздрава России, \\ Новосибирск, Россия
}

Несмотря на большое количество проведенных исследований, предикторы прогрессирования хронической сердечной недостаточности $(\mathrm{XCH})$ на фоне фибрилляции предсердий (ФП) остаются до конца не изученными, и число госпитализаций по поводу ХСН неуклонно растет.

Цель. Разработать персонифицированную оценку рисков развития и прогрессирования $\mathrm{XCH}$ при фибрилляции предсердий в сочетании с гипертонической болезнью и изучить предикторы прогрессирования ХCH на догоспитальном этапе.

Материал и методы. В проспективном когортном исследовании наблюдались 546 пациентов с артериальной гипертонией (АГ) и ФП и 238 пациентов с АГ без ФП в возрасте 45-60 лет. В процессе обследования определяли показатели гемодинамики и морфофункциональные показатели миокарда; изучалось содержание в плазме NT-фрагмента мозгового натрийуретического пептида (NT-proBNP) и галектина-3 как ранних маркеров миокардиальной дисфункции. Статистические расчеты проводили в программе Rstudio (version 0.99.879 - (C) 2009-2016 RStudio, Inc., USA, 250 Northern Ave, Boston, MA 02210 844-448-121, info@rstudio.com).

Результаты. Расчет и сравнение статистических показателей двух клинических групп показали, что в группе больных АГ и ФП средний уровень галектина-3 в сыворотке крови составил $29,44[12,7 ; 97,73]$ нг/мл, а в группе сравнения $-14,05[7,06 ; 14,76]$ нг/мл, $p<0,001$. Средний уровень NT-proBNP в группе АГ и ФП находился в пределах 289,02 пг/мл [140,92; 337,34], $p<0,277$, а в группе сравнения - 117 пг/мл $[96 ; 165,5], p<0,001$. На модели логистической регрессии из однофакторных моделей выявлены статистически значимые предикторы неблагоприятного течения заболевания. Так, в группе больных АГ и ФП с увеличением галектина-3 и NT-proBNP увеличиваются риски повторной госпитализации. Увеличение галектина-3 на одну единицу повышает риск повторной госпитализации в $1,05[1,02 ; 1,12]$ раза, $(p=0,024)$; повышение NT-proBNP на 1 пг/мл повышает риск развития ХСН в $1,01[1 ; 1,02]$ раза $(p=0,041)$. В течение года в группе АГ и ФП процент госпитализаций составил 25,47 \% [34 \%; $60 \%$ ], в то время как в группе АГ без ФП 6,17\% [8\%; $32 \%], p<0,003$.

Заключение. У больных с ФП и АГ отмечается достоверное повышение NT-proBNP и галектина-3 по сравнению с больными АГ и синусовым ритмом, что можно рассматривать в качестве предикторов прогрессирования сердечной недостаточности и повторной госпитализации, учитывая значение двух последних как маркеров миокардиальной дисфункции. Разработана математическая формула многофакторной регрессии для предсказания риска повторной госпитализации в группе в группе больных АГ и ФП: Р (повторной госпитализации) $=\frac{e^{z}}{1+e^{z}}$, где $z=-4,62+2,66 \cdot \mathrm{XCH} \mathrm{ФК} \mathrm{+} \mathrm{0,05} \cdot$ Галлектин $-2,70 \cdot 2,15$ возраст $+2,25 \cdot \mathrm{NT}$-proBNP; $\mathrm{P}$ (повторной госпитализации) - вероятность повторной госпитализации; $e^{z}-$ функция экспоненты в степени $z$.

DOI $10.52727 / 2078-256 X-2021-17-3-43-44$

\section{НЕИНВАЗИВНОЕ ПОВЕРХНОСТНОЕ КАРТИРОВАНИЕ ПРЕДСЕРДНЫХ И ЖЕЛУДОЧКОВЫХ АРИТМИЙ}

\author{
М.С. Хлынин, С.Ю. Усенков, Р.Е. Баталов, Е.А. Арчаков, С.В. Попов, Т.А. Атабеков
}

Научно-исследовательский институт кардиологии, Томский НИМЦ, Томск, Россия

Введение. В настоящее время наиболее эффективным методом лечения различных аритмий признается радиочастотная аблация (РЧА), которая позволяет радикально устранить нару- шения ритма сердца (НРС) без последующего приема антиаритмических препаратов. Однако для высокой эффективности данной интервенционной процедуры необходима точная топи- 